\title{
Changes of the Structures and Properties of Corn Stover during Acid Sulfite Pretreatment for Improved Enzymatic Hydrolysis
}

\author{
Liping Tan, ${ }^{\mathrm{a}, \mathrm{b}}$ Zhongyang Liu, ${ }^{\mathrm{b}}$ Tongjun Liu, ${ }^{\mathrm{a}, \mathrm{b}, *}$ and Tengfei Wang ${ }^{\mathrm{a}, \mathrm{b}, *}$
}

\begin{abstract}
Acid sulfite pretreatment has been shown to be an effective and practical method for improving the enzymatic hydrolysis of corn stover (CS) for bioethanol production. In the present study, the changes in the structures and properties of CS during the acid sulfite pretreatment process were investigated. The results showed that the crystallinity of cellulose in CS was increased by the pretreatment. The recalcitrant structure of untreated CS was destroyed by the acid sulfite pretreatment, which led to an increase in surface area being exposed. Thermogravimetric analysis indicated that the temperature for the maximum mass loss rate of the acid sulfite-pretreated $\mathrm{CS}$ shifted by $40{ }^{\circ} \mathrm{C}$ compared to that of the untreated CS. Large amounts of gas species, such as $\mathrm{CO}_{2}, \mathrm{CO}, \mathrm{CH}_{4}$, and $\mathrm{H}_{2} \mathrm{O}$, were released during the pyrolysis process. This work provides a theoretical reference to the determination of the optimal pretreatment parameters for the conversion of CS into bioethanol.
\end{abstract}

Keywords: Corn stover; Acid sulfite pretreatment; Cellulose crystallinity; Specific surface area; Thermogravimetry-infrared spectroscopy

Contact information: a: State Key Laboratory of Biobased Material and Green Papermaking, Qilu University of Technology, Shandong Academy of Sciences, Jinan, 250353, China; b: Shandong Provincial Key Laboratory of Microbial Engineering, Department of Bioengineering, Qilu University of Technology, Shandong Academy of Sciences, Jinan, 250353, China;

*Corresponding authors: liutongjun@outlook.com; wangtengfei1981@163.com

\section{INTRODUCTION}

Since the 21st century, the increasing demand for energy has led to a rapid depletion of fossil fuels and to serious environmental problems. Biomass energy has become favored in many fields because of its rich source, environmental compatibility, and renewable properties (Kim et al. 2019). The degradation of lignocellulosic biomass into fermentable sugars to produce bioethanol is one of the hot topics in biomass-to-energy conversion research (Mafakheri and Nasiri 2014; Rastogi and Shrivastava 2017; Chan et al. 2019). Different lignocellulosic biomasses, such as oil palm empty fruit bunch (Tan et al. 2013; Derman et al. 2018), sugarcane bagasse (Hilares et al. 2018), bamboo (Yang et al. 2019), corncob (Kleingesinds et al. 2018), and rice straw (Chiranjeevi et al. 2018), have been used for bioethanol production.

However, the complex structures of lignocellulosic biomasses, as well as the physical encapsulation of cellulose by lignin and hemicelluloses, make lignocellulose nearly inaccessible for enzymes, which seriously affect the enzymatic hydrolysis efficiency (Mika et al. 2017). Therefore, lignocellulosic biomasses are usually pretreated to achieve desired enzymatic hydrolysis efficiency for the biomass-to-energy conversion. Many pretreatment methods have been investigated to improve the enzymatic hydrolysis process 
for bioethanol production, which can be roughly classified into chemical, physical, biological, physico-chemical, and combined pretreatments (Kumari and Singh 2018). Among these pretreatment techniques, acid sulfite pretreatment has been reported as one of the most efficient processes (Tan et al. 2016, 2019; Xing et al. 2016).

Previous research work (Tan et al. 2019) demonstrated that acid sulfite pretreatment is an effective and practical method to improve enzymatic hydrolysis of corn stover (CS) for the production of bioethanol with higher conversion rates of cellulose and higher yields of ethanol. However, the possible mechanisms of acid sulfite pretreatment have been rarely discussed. The present work monitored the changes in the structures and properties of CS during the acid sulfite pretreatment process to understand how the pretreatment improves the enzymatic hydrolysis efficiency of CS. The properties of untreated and acid sulfite-pretreated CS were characterized by scanning electron microscopy (SEM), X-ray diffraction (XRD), specific surface area analysis, and thermogravimetry-infrared spectroscopy (TG-IR), to provide theoretical reference for determining the optimal process conditions for the conversion of the biomass into bioethanol.

\section{EXPERIMENTAL}

\section{Materials}

Corn stover was obtained from Weifang, Shandong Province, P. R. China. It was air-dried to a constant moisture content (approximately 10\%), cut to small pieces of 2 to 3 $\mathrm{cm}$ long, and was sealed in bags and stored at room temperature. Cellic ${ }^{\circledR} \mathrm{CTec} 2$ (cellulase enzyme) was purchased from Novozymes (Beijing, P. R. China); its filter paper activity unit (FPU) was determined to be $90 \mathrm{FPU} / \mathrm{mL}$. Other chemical reagents, such as sodium bisulfite, sulfuric acid, and ethanol, were of analytical grade (Aladdin Bio-Chem Technology Co., Ltd., Shanghai, China).

\section{Methods}

Acid sulfite pretreatment of CS

Acid sulfite pretreatment was completed in a rotary pressure digester (ZQS-3; Qinggong Jixie Factory of Shaanxi University of Science and Technology, Xianyang, Shaanxi Province, P. R. China) that was electrically heated. Pretreatments were performed at $170{ }^{\circ} \mathrm{C}$ for $30 \mathrm{~min}$ in a solution of sodium bisulfite consisting of $7 \% \mathrm{NaHSO}_{3}$ and $1 \%$ $\mathrm{H}_{2} \mathrm{SO}_{4}$ (based on dry mass of CS, w/w). The ratio of CS (dry mass, g) to liquor (volume, $\mathrm{mL}$ ) was 1:4. The insoluble solids were separated from the spent liquor using a bag filter; the solids were retained for further analysis.

\section{Enzymatic hydrolysis}

The untreated and acid sulfite-pretreated CS were hydrolyzed with cellulase in 50$\mathrm{mL}$ flasks to evaluate their enzymatic digestibility under the following conditions: $0.05 \mathrm{M}$ sodium acetate buffer at $4.8 \mathrm{pH} ; 48{ }^{\circ} \mathrm{C} ; 2 \%$ solid (dry matter basis); $150 \mathrm{rpm}$ shaking; and $10 \mathrm{FPU} / \mathrm{g}$ cellulase dosage (dry sample basis). Aliquots $(200 \mu \mathrm{L})$ were taken from the mixture at the specified time intervals, centrifuged, and analyzed by high-performance liquid chromatography (HPLC) with the centrifugal supernatant to determine the contents of glucose and xylose. The conversion rates of cellulose and xylan were calculated using the following equations: 


$$
\begin{aligned}
& \text { Conversion of cellulose }(\%)=\frac{\text { Glucose released from enzymatic hydrolysis }(\mathrm{mg}) \times 0.9}{\text { Sample mass }(\mathrm{mg}) \times \text { Glucan content }(\%)} \times 100 \% \\
& \text { Conversion of xylan }(\%)=\frac{\text { Glucose released from enzymatic hydrolysis }(\mathrm{mg}) \times 0.88}{\text { Sample mass }(\mathrm{mg}) \times \text { Xylan content }(\%)} \times 100 \%
\end{aligned}
$$

\section{XRD measurement}

X-ray diffraction patterns were measured using a Bruker D8 Advance Diffractometer (Bruker BioSpin GmbH, Rheinstetten, Germany). The crystallinity was calculated by the method reported by Kim and Holtzapple (2006).

\section{Brunauer-Emmett-Teller (BET) analysis}

The specific surface areas of the untreated and acid sulfite-pretreated CS were measured by the BET nitrogen adsorption isotherm method using a V-Sorb X800 series analyzer (Gold APP Instruments Corp., Beijing, P. R., China).

\section{SEM observation}

The untreated and acid sulfite-pretreated CS were dried, fixed on the sample holder with a conductive tape, sputter-coated with a layer of gold (ETD-2000; Beijing Elaborate Technology Development Ltd., Beijing, China), and imaged with a JEOL JSM-6700F scanning electron microscope (JEOL Ltd., Tokyo, Japan) under the SEM operated at 20 KV at the magnification of 20 to 20,000 .

\section{TG-IR analysis}

The untreated and acid sulfite-pretreated CS were loaded into ceramic crucibles that were placed into the furnace of the thermogravimetric analyzer (PerkinElmer TGA 4000; PerkinElmer Inc., Waltham, MA, USA), which was connected to an infrared (IR) spectrometer (PerkinElmer Spectrum Two; PerkinElmer Inc., Waltham, MA, USA). The system was first purged with high-purity nitrogen. The furnace temperature was then increased from $30{ }^{\circ} \mathrm{C}$ to $800{ }^{\circ} \mathrm{C}$ at the heating rate of $50{ }^{\circ} \mathrm{C} / \mathrm{min}$ under a $20 \mathrm{~mL} / \mathrm{min}$ nitrogen flow to obtain the thermogravimetric (TG) curve and its derivative thermogravimetric (DTG) curve.

Meanwhile, the gaseous decomposition products were introduced into the gas reservoir of the IR spectrometer via a transfer line to determine the real-time composition analysis. The temperature of the transfer line was set to $250{ }^{\circ} \mathrm{C}$. The IR spectra were recorded over the range of 400 to $4000 \mathrm{~cm}^{-1}$ at a resolution of $4 \mathrm{~cm}^{-1}$.

\section{Sugar and lignin analysis}

The contents of glucan, xylan, and lignin in the untreated and acid sulfite-pretreated CS samples were determined by the National Renewable Energy Laboratory (NREL) method (Sluiter et al. 2011). The contents of glucose and xylose were measured using a HPLC instrument (LC-20AT; Shimadzu Corp., Kyoto, Japan) equipped with a refractive index detector (Shimadzu Corp., Kyoto, Japan) and an Aminex HPX-87H column (BioRad Laboratories, Hercules, CA, USA). The column temperature was maintained at $65^{\circ} \mathrm{C}$ with a $0.6 \mathrm{~mL} / \mathrm{min} 5 \mathrm{mM} \mathrm{H}_{2} \mathrm{SO}_{4}$ mobile phase flow rate. 


\section{RESULTS AND DISCUSSION}

\section{Chemical Compositions and Enzymatic Hydrolysis Efficiencies of the Untreated and Acid Sulfite-pretreated CS}

The CS was pretreated with $7 \%$ sodium bisulfite and $1 \%$ sulfuric acid at $170{ }^{\circ} \mathrm{C}$ for $30 \mathrm{~min}$ as described in a previous publication (Tan et al. 2019). Table 1 lists the chemical compositions of the CS before and after the acid sulfite pretreatment, as well as the enzymatic conversion rates of glucan and xylan in the untreated and pretreated CS. In general, hemicelluloses are sensitive to acid and thus easy to degrade under acidic conditions (Sahoo et al. 2018), whereas lignin is sensitive to alkali and easy to dissolve under alkaline conditions (Kan et al. 2018). The acid sulfite pretreatment can be conducted in cooking liquors with wide $\mathrm{pH}$ and temperature ranges. Depending on the $\mathrm{pH}$ of the pretreatment liquor at a specific pretreatment temperature, either sulfite $\left(\mathrm{SO}_{3}{ }^{2-}\right)$, bisulfite $\left(\mathrm{HSO}_{3}{ }^{-}\right)$, or a combination of two of the three reagents (e.g., sulfite, bisulfite, and sulfur dioxide $\left(\mathrm{SO}_{2}\right.$, or $\left.\mathrm{H}_{2} \mathrm{SO}_{3}\right)$ ) can be used as the active reagents. Hemicelluloses can be partially degraded or dissolved under acidic conditions. The sulfite, bisulfite, and sulfur dioxide can attack the $\mathrm{C} \alpha$ or $\mathrm{C} \gamma$ position of lignin (i.e., sulfonation reactions), which can increase the hydrophilicity of the lignin, which promotes its dissolution (Tan et al. 2016; Liu et al. 2018; Ren et al. 2018; Tan et al. 2019). In the present study, the acid sulfite pretreatment caused a $75.08 \%$ loss of xylan and a $33.98 \%$ loss of lignin, which suggested that both of them were degraded or dissolved to some extent during the process. The loss of glucan was low (only approximately $3 \%$ ), which indicated that the glucan was retained in the raw material after the acid sulfite pretreatment. Enzymatic hydrolysis results indicated that the acid sulfite pretreatment appreciably increased the conversion rates of glucan and xylan to $80 \%$ and $86 \%$, respectively, which were $220 \%$ and $200 \%$ higher, respectively, than those obtained with the untreated CS. These results demonstrated that the acid sulfite pretreatment could greatly improve the enzymatic saccharification efficiency of CS.

Table 1. Yield from Acid Sulfite Pretreatment, and the Changes of the Chemical Composition and Enzymatic Hydrolysis Efficiency Caused by the Acid Sulfite Pretreatment

\begin{tabular}{|c|c|c|c|c|c|c|}
\hline Sample & $\begin{array}{l}\text { Yield } \\
(\%)\end{array}$ & $\begin{array}{l}\text { Glucan }(\%) \\
\left(\% \operatorname{loss}^{* *}\right)\end{array}$ & $\begin{array}{l}\text { Xylan }(\%) \\
\left(\% \text { loss }^{* *}\right)\end{array}$ & $\begin{array}{c}\text { Total Lignin } \\
(\%) \\
\left(\% \text { loss }^{\star \star}\right)\end{array}$ & $\begin{array}{c}24 \text { h Glucan } \\
\text { Conversion } \\
(\%)\end{array}$ & $\begin{array}{c}24 \text { h Xylan } \\
\text { Conversion } \\
(\%)\end{array}$ \\
\hline $\begin{array}{c}\text { Untreated } \\
\text { CS }\end{array}$ & - & $27.0 \pm 1.11$ & $13.02 \pm 0.62$ & $19.85 \pm 0.91$ & $25.03 \pm 1.15$ & $30.02 \pm 1.41$ \\
\hline $\begin{array}{l}\text { Acid sulfite- } \\
\text { pretreated } \\
\text { CS }\end{array}$ & 54.99 & $\begin{array}{c}47.49 \pm 1.23 \\
\quad(3.27)\end{array}$ & $\begin{array}{c}5.90 \pm 1.08 \\
(75.08)\end{array}$ & $\begin{array}{c}23.83 \pm 1.65 \\
(33.98)\end{array}$ & $80.43 \pm 3.11$ & $86.42 \pm 2.66$ \\
\hline \multicolumn{7}{|c|}{$\begin{array}{l}{ }^{*} \mathrm{NaHSO}_{3} \text { dosage based on untreated } \mathrm{CS} ; \\
\text { **glucan, xylan, and lignin losses based on the glucan, xylan, and lignin contents in the } \\
\text { untreated CS; and } \\
\text { *** pretreatment conditions: } 7 \% \mathrm{NaHSO}_{3}, 1 \% \mathrm{H}_{2} \mathrm{SO}_{4}, 170{ }^{\circ} \mathrm{C} \text {, and } 30 \mathrm{~min}\end{array}$} \\
\hline
\end{tabular}

\section{Changes of the Cellulose Crystallinity of CS after Acid Sulfite Pretreatment}

Cellulose contains two regions: the crystalline region and the amorphous region. The proportion of cellulose that is crystalline relative to its whole is called the crystallinity of cellulose (Pena et al. 2019). Regardless of the interactions of lignin and hemicelluloses 
with cellulose, the crystallinity of lignocellulosic biomass is an important factor in determining its digestibility (Karimi and Taherzadeh 2016). Celluloses with low crystallinities usually exhibit much higher enzymatic hydrolysis efficiencies than the celluloses with high crystallinities (Zhao and Chen 2013). Figure 1 shows the XRD patterns of the CS before and after the acid sulfite pretreatment. It is clear that the acid sulfitepretreated CS appreciably enhanced the $2 \theta$ diffraction peaks at $c a .22 .4^{\circ}$ and $c a .18 .7^{\circ}$. The crystallinity of the pretreated CS was almost $85 \%$ higher than that of the untreated sample (Table 2). This observation can be explained by the fact that the acid sulfite process partially degrades the amorphous region, removes most of the hemicelluloses and part of the lignin, and rearranges the fiber structure of the CS, which results in a more highly ordered and relatively complete crystal structure (Sun et al. 2016). Another possible reason is that the pretreatment partially destroys the amorphous region of cellulose, changes the hemicellulose components, and thus leaves behind a higher proportion of cellulose crystalline domains within the CS (Chen et al. 2016). Although the pretreated CS showed a higher crystallinity than the untreated CS, it also showed higher accessibility to cellulase than the untreated CS.

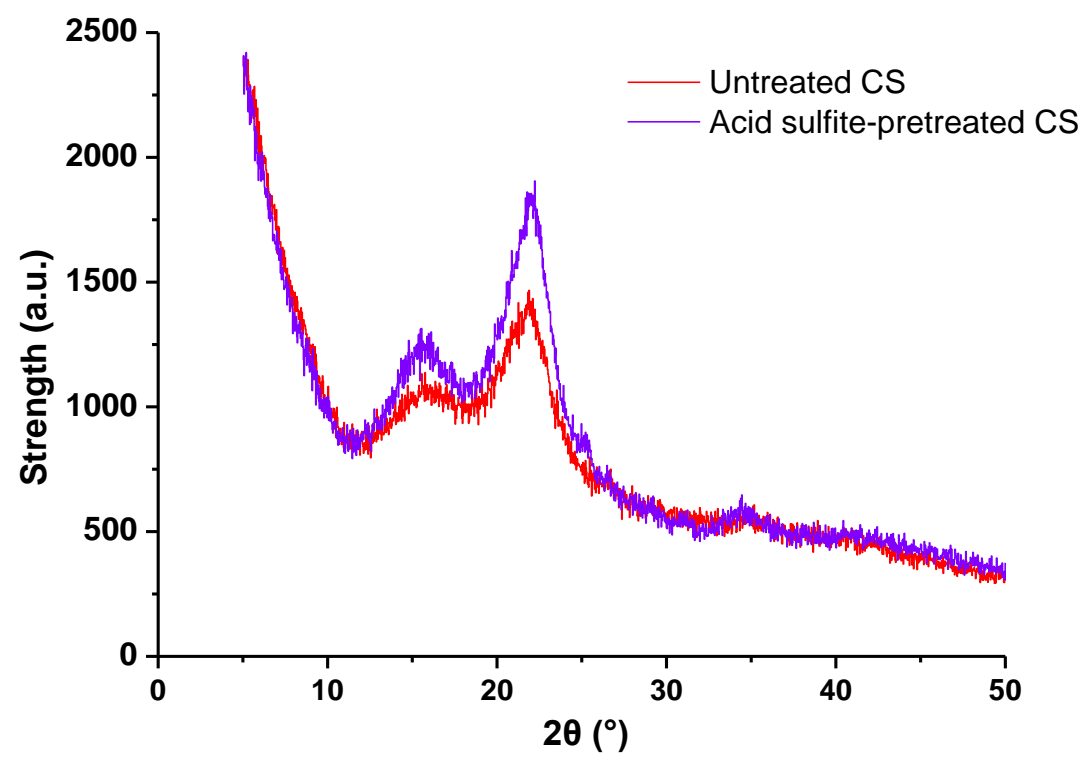

Fig. 1. XRD patterns of the CS before and after the acid sulfite pretreatment

Table 2. Changes in the Crystallinity Index of Cellulose and the Specific Surface Area of CS Caused by the Acid Sulfite Pretreatment

\begin{tabular}{|c|c|c|}
\hline Samples & Crystallinity (\%) & Specific Surface Area $\left(\mathrm{m}^{2} / \mathrm{g}\right)$ \\
\hline Untreated CS & 22.10 & 7.24 \\
\hline Acid sulfite-pretreated CS & 41.33 & 9.22 \\
\hline
\end{tabular}

\section{Changes of Surface Area of CS after Acid Sulfite Pretreatment}

The hydrolysis caused by the lignocellulolytic enzyme requires sufficient contacts between the lignocellulosic substrate and the enzyme to form a substrate-enzyme complex to release the sugars (Gupta and Verma 2015; Meng et al. 2015). Therefore, the accessible surface area of cellulose is considered as one of the most critical factors affecting the 
enzymatic hydrolysis yield and rate (Leu and Zhu 2013; Lu et al. 2019). A variety of analytical techniques has been applied to measure the surface areas of lignocellulosic substrates. Among these techniques, the BET method with nitrogen adsorption gives the accessible surface area of the substrate. The SEM imaging can be used to assess the substrate's external specific surface area.

\section{Qualitative assessment of external surface}

Figure 2 shows the SEM images of the corn leaves, corn husks, and core before and after the acid sulfite pretreatment. The husk and leaf surfaces of the untreated CS were orderly and densely structured. The acid sulfite destroyed the surface structure, which resulted in loose surfaces with obvious cracks and pores. Fine fibers were also observed. The surface of the untreated corn core was an ordered mesh-like structure, which was also disrupted by the pretreatment. More internal structures were then exposed, which increased the surface area. A larger external surface area is conducive to the contact between lignocellulolytic enzymes and fiber, and thus improves the enzymatic hydrolysis efficiency of cellulose (De Oliveira Santos et al. 2018).

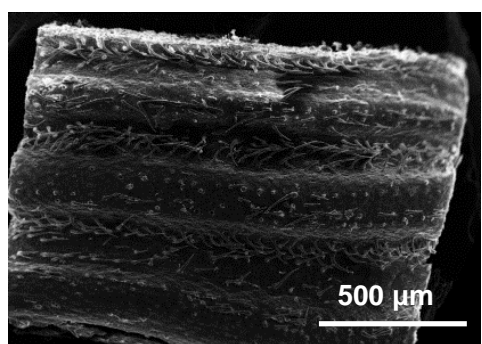

(a) Husk of CS

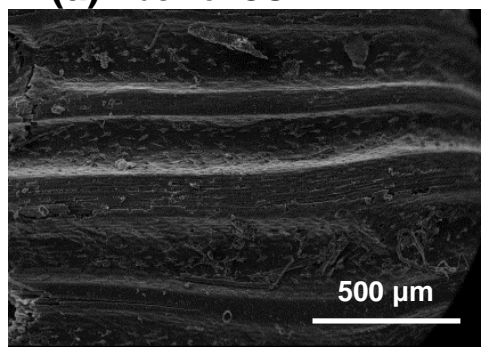

(d) Husk of Pretreated CS

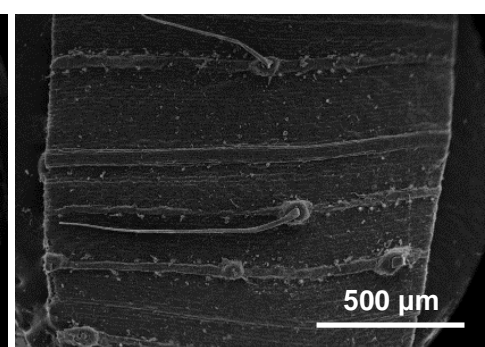

(b) Leaf of CS

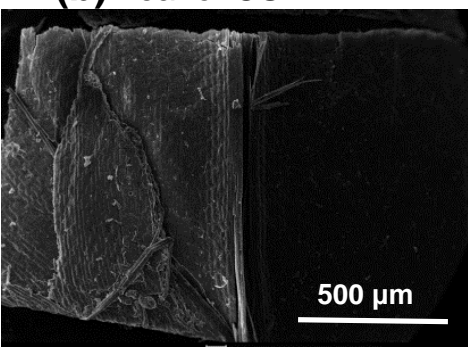

(e) Leaf of Pretreated CS

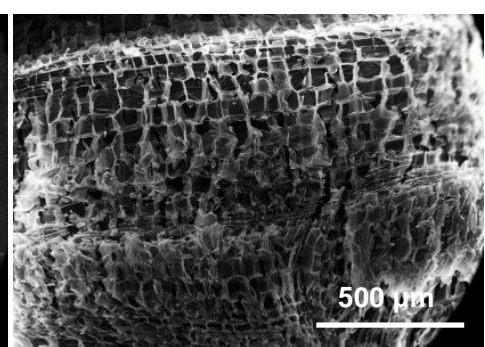

(c) Core of CS

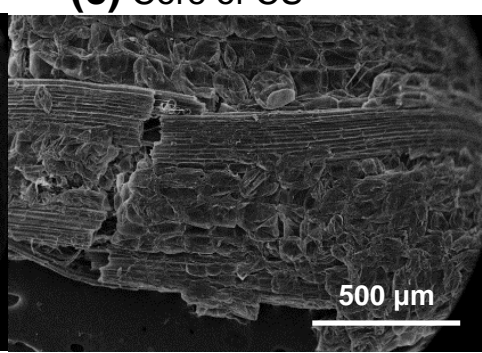

(f) Core of Pretreated CS

Fig. 2. SEM images $(\times 75)$ of CS before and after acid sulfite pretreatment

\section{Internal specific surface area}

Zhu et al. (2009) and Wang et al. (2012) measured the internal specific surface areas of biomass feedstocks before and after the pretreatment with the solvent-excluded surface area method. The authors noted that the pretreatment and the grinding increased the internal specific surface area, which greatly improved the enzymatic hydrolysis efficiency of the cellulose. In the present work, the internal specific surface areas of CS before and after the acid sulfite pretreatment were measured using the BET method based on the low temperature physical monolayer adsorption theory. As shown in Table 2 for the specific surface areas of the untreated and pretreated CS, the pretreatment increased the internal specific surface area from $7.24 \mathrm{~m}^{2} / \mathrm{g}$ to $9.22 \mathrm{~m}^{2} / \mathrm{g}$. The larger internal specific surface increased the accessibility for the lignocellulolytic enzyme to the substrate and thereby increased the enzymatic hydrolysis efficiency of the CS. 


\section{TG-IR Analyses of Untreated and Pretreated CS}

Thermal decomposition analysis

To evaluate the changes in the thermal properties of CS after the acid sulfite pretreatment, the TG and DTG curves of the CS were measured (Fig. 3).

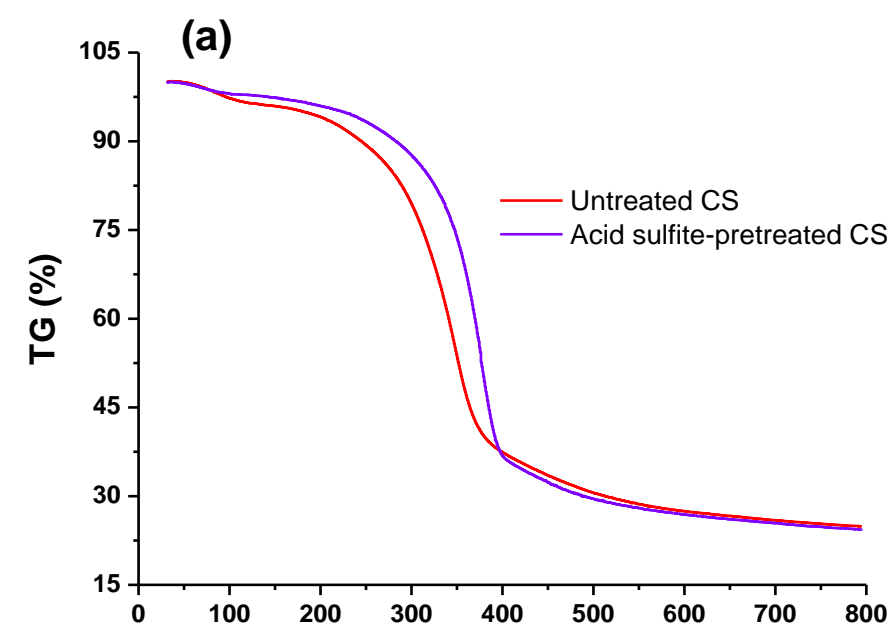

(b)

Temperature $\left({ }^{\circ} \mathrm{C}\right)$

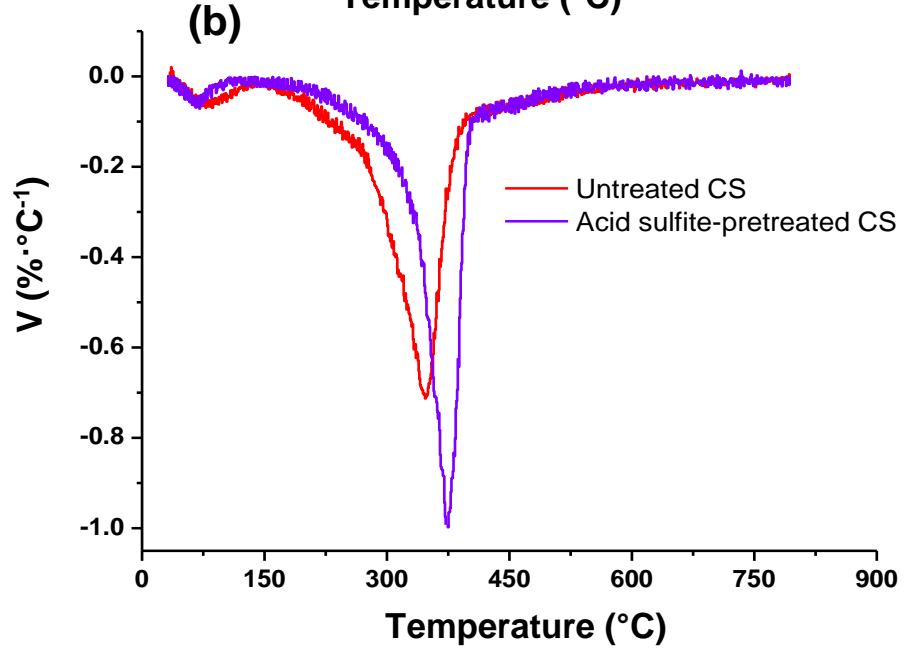

Fig. 3. TG (a) and DTG (b) curves of the untreated and acid sulfite-pretreated CS

Both untreated and pretreated CS exhibited three thermogravimetric mass loss regions, which included the loss of adsorbed water, the decomposition, and the carbonization of the substrate. The first mass loss occurred in the temperature range from room temperature to $150{ }^{\circ} \mathrm{C}$, which was attributed to the evaporation of adsorbed water; this stage laid the foundation for the next thermogravimetric decomposition stage (Amaral et al. 2019). The mass loss of the first stage was only 2 to $3 \%$, which was mainly due to the release of small molecular weight compounds that included $\mathrm{H}_{2} \mathrm{O}, \mathrm{CO}$, and $\mathrm{CO}_{2}(\mathrm{GaO}$ et al. 2013). In the decomposition stage, the labile hemicelluloses were softened at temperatures lower than $200{ }^{\circ} \mathrm{C}$ and were decomposed over the temperature range of 200 to $280{ }^{\circ} \mathrm{C}$ (which produced volatile products). Cellulose was softened in the temperature range of 200 to $400{ }^{\circ} \mathrm{C}$ and was decomposed over the temperature range of 240 to $350{ }^{\circ} \mathrm{C}$ (also producing volatile compounds) (Giuntoli et al. 2009). The decomposition 
temperature range of lignin was the widest; it was softened at temperatures below $200{ }^{\circ} \mathrm{C}$ and was mainly decomposed at 280 to $500{ }^{\circ} \mathrm{C}$ into charcoal (Wang et al. 2014). The DTG curves of both untreated and pretreated CS changed sharply in the temperature range of 150 to $420{ }^{\circ} \mathrm{C}$, which showed an obvious mass loss peak. However, the maximum mass loss rate of the untreated CS was observed at $345.63{ }^{\circ} \mathrm{C}$, whereas that of the pretreated CS shifted $\Delta 40{ }^{\circ} \mathrm{C}$ to $384.95{ }^{\circ} \mathrm{C}$. As discussed earlier, the pretreatment removed most of the hemicelluloses and part of the lignin and rearranged the fiber structure, which increased the crystallinity of the cellulose. Therefore, the temperature range of the softening and decomposition stage of the pretreated CS was greater than that of the untreated CS, which shifted the temperature for the maximum mass loss. The mass loss of the pretreated CS in this stage from its TG curve was calculated to be $c a$. 60\%. The CS is mainly decomposed into small molecular gases and large condensable volatiles during this thermogravimetric mass loss stage (Zabaniotou et al. 2008). The CS was carbonized over the temperature range of 420 to $800{ }^{\circ} \mathrm{C}$, which was mainly due to the slow decomposition of some lignin and ash. No obvious mass loss peak was observed with the DTG curve of this stage. The mass loss of the carbonization stage was ca. $11 \%$ and the residual mass was $c a .25 \%$.

\section{TG-IR spectral analysis}

Figure 4 shows the IR spectra of the thermal decomposition products of the untreated $\mathrm{CS}$ at $345^{\circ} \mathrm{C}$ and acid sulfite-pretreated $\mathrm{CS}$ at $385^{\circ} \mathrm{C}$ (i.e., at the temperatures where the maximum mass losses were observed).

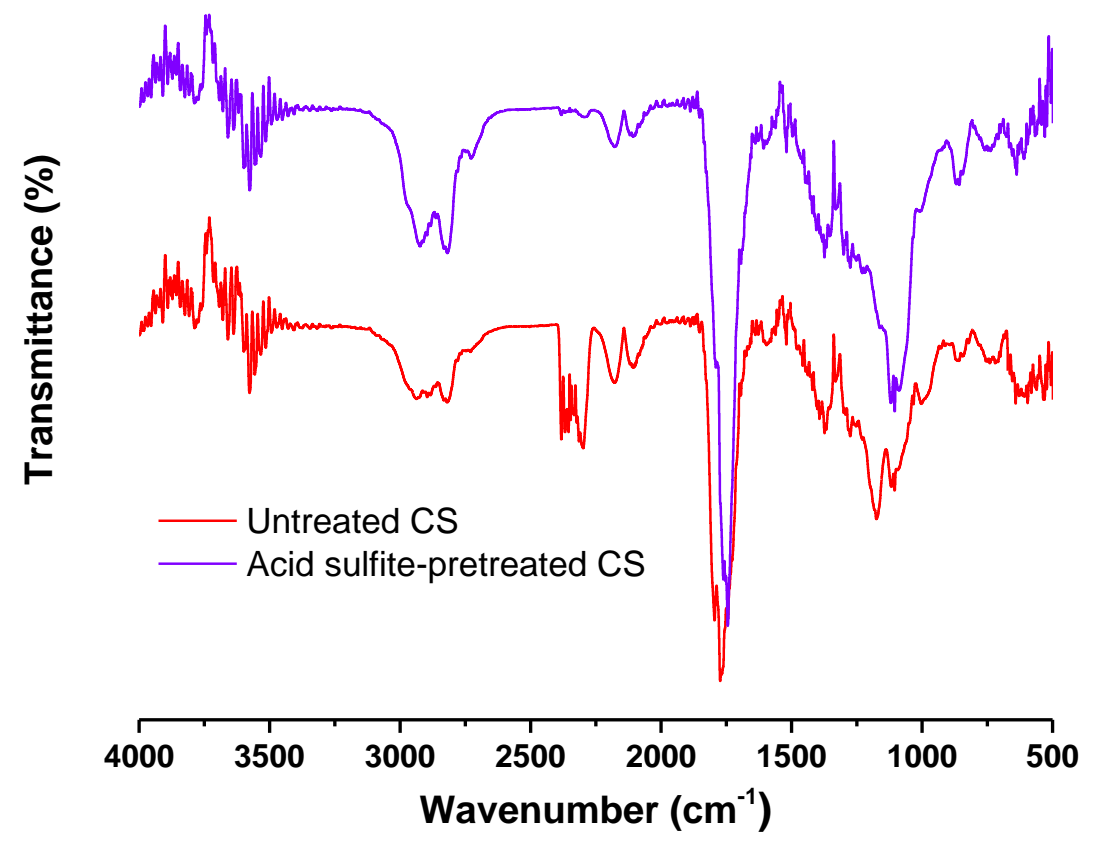

Fig. 4. IR spectra of the untreated and acid sulfite-pretreated CS as heated at $345^{\circ} \mathrm{C}$ and 385 ${ }^{\circ} \mathrm{C}$, respectively, during the $\mathrm{TG}$ analysis

The broad and weak peaks in the range of 4000 to $3400 \mathrm{~cm}^{-1}$ were assigned to the symmetric and antisymmetric stretching of the $\mathrm{O}-\mathrm{H}$ bond in water, possibly from the water and the polycondensation of hydroxyl groups (Gu et al. 2013). The stretching vibration peaks for the $\mathrm{C}-\mathrm{H}$ bond were observed in the range of 3200 to $2700 \mathrm{~cm}^{-1}$, which indicated 
that the thermal decomposition produced $\mathrm{CH}_{4}$ that possibly resulted from the methoxy $\left(\mathrm{CH}_{3} \mathrm{O}-\right)$, methyl $\left(-\mathrm{CH}_{3}\right)$, and methylene $\left(-\mathrm{CH}_{2}\right)$ groups. Carbon dioxide $\left(\mathrm{CO}_{2}\right)$ had a characteristic absorption in the range of 2400 to $2298 \mathrm{~cm}^{-1}$, which mainly came from decarboxylation reactions and cleavage reactions of carbonyl groups. The peaks at 2180 to $2100 \mathrm{~cm}^{-1}$ are ascribed to the $\mathrm{CO}$ produced from the cleavages of ether bonds (C-O-C) and carbonyl bonds $(\mathrm{C}=\mathrm{O})$ (Liu et al. 2011). The peaks in these two regions of the untreated $\mathrm{CS}$ had stronger absorptions than those observed in the pretreated CS. This observation can be explained by the decomposition of the corresponding components in the untreated CS that occurred earlier than those of the pretreated sample; thus, some of the $\mathrm{CO}_{2}$ and $\mathrm{CO}$ produced was released before the measurement, as was observed in the TG analysis. The absorption peaks in the range of 1830 to $1695 \mathrm{~cm}^{-1}$ were assigned to the stretching vibration of the $\mathrm{C}=\mathrm{O}$ bond of the decomposition gaseous products, such as aldehydes, ketones, and organic acids. The absorption peaks of the pretreated CS were stronger than the absorption peaks of the untreated sample in the same region, which was possibly due to more acetyl groups being exposed in the pretreated sample (Wang et al. 2015). The absorption peaks in the range of 1650 to $1000 \mathrm{~cm}^{-1}$ were mainly due to the in-plane bending vibrations of benzene ring and $\mathrm{C}-\mathrm{H}$ bonds, as well as the vibrations of $\mathrm{C}-\mathrm{O}$ and $\mathrm{C}-\mathrm{C}$ skeletons, which indicated that there were alcohols, phenols, and lipids in the decomposition gaseous products from the CS.

\section{CONCLUSIONS}

The action mechanism of acid sulfite pretreatment was explored by studying the structures and properties of the CS before and after the pretreatment.

1. The process made the surface of CS rough, increased its specific surface area, and exposed more fine fibers. These changes were accompanied with obvious cracks, a seriously damaged surface, and loose structures. The changes caused by the pretreatment dramatically increased the enzymatic hydrolysis efficiency of the CS.

2. It was also observed from the TG-IR analysis that both untreated and pretreated CS exhibited three thermogravimetric mass loss regions. The thermal decomposition characteristics of CS before and after acid sulfite pretreatment were slightly different, which was related to the proportion of cellulose, hemicellulose, and lignin in CS. The volatile gases from thermal decomposition were mainly composed of small molecules $\mathrm{CO}, \mathrm{H}_{2} \mathrm{O}, \mathrm{CH}_{4}$, and $\mathrm{CO}_{2}$.

\section{ACKNOWLEDGMENTS}

This study was supported by the Natural Science Foundation of Shandong Province (Grant No. ZR2017LC015). 


\section{REFERENCES CITED}

Amaral, H. R., Cipriano, D. F., Santos, M. S., Schettino, Jr., M. A., Ferreti, J. V. T., Meirelles, C. S., Pereira, V. S., Cunha, A. G., Emmerich, F. G., and Freitas, J. C. C. (2019). "Production of high-purity cellulose, cellulose acetate and cellulose-silica composite from babassu coconut shells," Carbohydrate Polymers 210, 127-134. DOI: 10.1016/j.carbpol.2019.01.061

Chan, Y. H., Cheah, K. W., How, B. S., Loy, A. C. M., Shahbaz, M., Singh, H. K. G., Yusuf, N. R., Shuhaili, A. F. A., Yusup, S., Ghani, W. A. W. A. K., et al. (2019). "An overview of biomass thermochemical conversion technologies in Malaysia," Science of The Total Environment 680, 105-123. DOI: 10.1016/j.scitotenv.2019.04.211

Chen, L., Li, J., Lu, M., Guo, X., Zhang, H., and Han, L. (2016). "Integrated chemical and multi-scale structural analyses for the processes of acid pretreatment and enzymatic hydrolysis of corn stover," Carbohydrate Polymers 141, 1-9. DOI: 10.1016/j.carbpol.2015.12.079

Chiranjeevi, T., Mattam, A. J., Vishwakarma, K. K., Uma, A., Peddy, V. C. R., Gandham, S., and Velankar, H. R. (2018). "Assisted single-step acid pretreatment process for enhanced delignification of rice straw for bioethanol production," ACS Sustainable Chemistry and Engineering 6(7), 8762-8774. DOI:

10.1021/acssuschemeng.8b01113

De Oliveira Santos, V. T., Siqueira, G., Milagres, A. M. F., and Ferraz, A. (2018). "Role of hemicellulose removal during dilute acid pretreatment on the cellulose accessibility and enzymatic hydrolysis of compositionally diverse sugarcane hybrids," Industrial Crops and Products 111, 722-730. DOI: 10.1016/j.indcrop.2017.11.053

Derman, E., Abdulla, R., Marbawi, H., and Sabullah, M. K. (2018). "Oil palm empty fruit bunches as a promising feedstock for bioethanol production in Malaysia," Renewable Energy 129(Part A), 285-298. DOI: 10.1016/j.renene.2018.06.003

Gao, N., Li, A., Quan, C., Du, L., and Duan, Y. (2013). "TG-FTIR and Py-GC/MS analysis on pyrolysis and combustion of pine sawdust," Journal of Analytical and Applied Pyrolysis 100, 26-32. DOI: 10.1016/j.jaap.2012.11.009

Giuntoli, J., De Jong, W., Arvelakis, S., Spliethoff, H., and Verkooijen, A. H. M. (2009). "Quantitative and kinetic TG-FTIR study of biomass residue pyrolysis: Dry distiller's grains with solubles (DDGS) and chicken manure," Journal of Analytical and Applied Pyrolysis 85(1-2), 301-312. DOI: 10.1016/j.jaap.2008.12.007

Gu, X., Ma, X., Li, L., Liu, C., Cheng, K., and Li, Z. (2013). "Pyrolysis of poplar wood sawdust by TG-FTIR and Py-GC/MS," Journal of Analytical and Applied Pyrolysis 102, 16-23. DOI: 10.1016/j.jaap.2013.04.009

Gupta, A., and Verma, J. P. (2015). "Sustainable bio-ethanol production from agroresidues: A review," Renewable and Sustainable Energy Reviews 41, 550-567. DOI: 10.1016/j.rser.2014.08.032

Hilares, R. T., Kamoei, D. V., Ahmed, M. A., Silva, S. S., Han, J., and Santos, J. C. (2018). "A new approach for bioethanol production from sugarcane bagasse using hydrodynamic cavitation assisted-pretreatment and column reactors," Ultrasonics Sonochemistry 43, 219-226. DOI: 10.1016/j.ultsonch.2018.01.016

Kan, X., Zhang, J., Tong, Y. W., and Wang, C. (2018). 'Overall evaluation of microwave-assisted alkali pretreatment for enhancement of biomethane production from brewers' spent grain," Energy Conversion and Management 158, 315-326. DOI: 10.1016/j.enconman.2017.12.088 
Karimi, K., and Taherzadeh, M. J. (2016). "A critical review of analytical methods in pretreatment of lignocelluloses: Composition, imaging, and crystallinity," Bioresource Technology 200, 1008-1018. DOI: 10.1016/j.biortech.2015.11.022

Kim, J. Y., Lee, H. W., Lee, S. M., Jae, J., and Park, Y. K. (2019). “Overview of the recent advances in lignocellulose liquefaction for producing biofuels, bio-based materials and chemicals," Bioresource Technology 279, 373-384. DOI: 10.1016/j.biortech.2019.01.055

Kim, S., and Holtzapple, M. T. (2006). "Effect of structural features on enzyme digestibility of corn stover," Bioresource Technology 97(4), 583-591. DOI: 10.1016/j.biortech.2005.03.040

Kleingesinds, E. K., José, Á. H. M., Brumano, L. P., Silva-Fernandes, T., Rodrigues, Jr., D., and Rodrigues, R.C.L.B. (2018). "Intensification of bioethanol production by using Tween 80 to enhance dilute acid pretreatment and enzymatic saccharification of corncob," Industrial Crops and Products 124, 166-176. DOI: 10.1016/j.indcrop.2018.07.037

Kumari, D., and Singh, R. (2018). "Pretreatment of lignocellulosic wastes for biofuel production: A critical review," Renewable and Sustainable Energy Reviews 90, 877891. DOI: 10.1016/j.rser.2018.03.111

Leu, S. Y., and Zhu, J. Y. (2013). "Substrate-related factors affecting enzymatic saccharification of lignocelluloses: Our recent understanding," Bioenergy Research 6(2), 405-415. DOI: 10.1007/s12155-012-9276-1

Liu, L., Ren, J., Zhang, Y., Liu, X., and Ouyang, J. (2018). "Simultaneously separation of xylo-oligosaccharide and lignosulfonate from wheat straw magnesium bisulfite pretreatment spent liquor using ion exchange resin," Bioresource Technology 249, 189-195. DOI: 10.1016/j.biortech.2017.09.207

Liu, Q., Zhong, Z., Wang, S., and Luo, Z. (2011). "Interactions of biomass components during pyrolysis: A TG-FTIR study," Journal of Analytical and Applied Pyrolysis 90(2), 213-218. DOI: 10.1016/j.jaap.2010.12.009

Lu, M., Li, J., Han, L., and Xiao, W. (2019). "An aggregated understanding of cellulase adsorption and hydrolysis for ball-milled cellulose," Bioresource Technology 273, 17. DOI: 10.1016/j.biortech.2018.10.037

Mafakheri, F., and Nasiri, F. (2014). "Modeling of biomass-to-energy supply chain operations: Applications, challenges and research directions," Energy Policy 67, 116126. DOI: 10.1016/j.enpol.2013.11.071

Meng, X., Wells, T., Sun, Q., Huang, F., and Ragauskas, A. (2015). "Insights into the effect of dilute acid, hot water or alkaline pretreatment on the cellulose accessible surface area and the overall porosity of Populus," Green Chemistry 17(8), 4239-4246. DOI: $10.1039 / \mathrm{C} 5 \mathrm{GC} 00689 \mathrm{~A}$

Mika, L. T., Csefalvay, E., and Nemeth, A. (2017). "Catalytic conversion of carbohydrates to initial platform chemicals: Chemistry and sustainability," Chemical Reviews 118(2), 505-613. DOI: 10.1021/acs.chemrev.7b00395

Pena, C. A., Soto, A., King, A. W. T., and Rodríguez, H. (2019). "Improved reactivity of cellulose via its crystallinity reduction by non-dissolving pretreatment with an ionic liquid," ACS Sustainable Chemistry and Engineering 7(10), 9164-9171. DOI: 10.1021/acssuschemeng.8b06357

Rastogi, M., and Shrivastava, S. (2017). "Recent advances in second generation bioethanol production: An insight to pretreatment, saccharification and fermentation 
processes," Renewable and Sustainable Energy Reviews 80, 330-340. DOI: 10.1016/j.rser.2017.05.225

Ren, J., Liu, L., Zhou, J., Li, X., and Ouyang, J. (2018). “Co-production of ethanol, xylooligosaccharides and magnesium lignosulfonate from wheat straw by a controlled magnesium bisulfite pretreatment (MBSP)," Industrial Crops and Products 113, 128134. DOI: 10.1016/j.indcrop.2018.01.026

Sahoo, D., Ummalyma, S. B., Okram, A. K., Pandey, A., Sankar, M., and Sukumaran, R. K. (2018). "Effect of dilute acid pretreatment of wild rice grass (Zizania latifolia) from Loktak Lake for enzymatic hydrolysis," Bioresource Technology 253, 252-255. DOI: 10.1016/j.biortech.2018.01.048

Sluiter, A., Hames, B., Ruiz, R., Scarlata, C., Sluitter, J., Templeton, D., and Crocker, D. (2011). Determination of Structural Carbohydrates and Lignin in Biomass,

Laboratory Analytical Procedure (LAP) (NREL/TP-510-42618), National Renewable Energy Laboratory, Golden, CO, USA.

Sun, S., Sun, S., Cao, X., and Sun, R. (2016). "The role of pretreatment in improving the enzymatic hydrolysis of lignocellulosic materials," Bioresource Technology 199, 4958. DOI: 10.1016/j.biortech.2015.08.061

Tan, L., Liu, Z., Liu, T., and Wang, F. (2019). "Efficient fractionation of corn stover by bisulfite pretreatment for the production of bioethanol and high value products," BioResources 14(3), 6501-6515. DOI: 10.15376/biores.14.3.6501-6515

Tan, L., Wang, M., Li, X., Li, H., Zhao, J., Qu, Y., Choo, Y. M., and Loh, S. K. (2016). "Fractionation of oil palm empty fruit bunch by bisulfite pretreatment for the production of bioethanol and high value products," Bioresource Technology 200, 572-578. DOI: 10.1016/j.biortech.2015.10.079

Tan, L. P., Yu, Y. C., Li, X. Z., Zhao, J., Qu, Y., Choo, Y. M., and Loh, S. K. (2013). "Pretreatment of empty fruit bunch from oil palm for fuel ethanol production and proposed biorefinery process," Bioresource Technology 135, 275-282. DOI: 10.1016/j.biortech.2012.10.134

Wang, Q., He, Z., Zhu, Z., Zhang, Y. H., Ni, Y., Luo, X., and Zhu, J. (2012). "Evaluations of cellulose accessibilities of lignocelluloses by solute exclusion and protein adsorption techniques," Biotechnology and Bioengineering 109(2), 381-389. DOI: 10.1002/bit.23330

Wang, S., Lin, H., Ru, B., Sun, W., Wang, Y., and Luo, Z. (2014). "Comparison of the pyrolysis behavior of pyrolytic lignin and milled wood lignin by using TG-FTIR analysis," Journal of Analytical and Applied Pyrolysis 108, 78-85. DOI: 10.1016/j.jaap.2014.05.014

Wang, S., Ru, B., Lin, H., and Sun, W. (2015). "Pyrolysis behaviors of four $O$-acetylpreserved hemicelluloses isolated from hardwoods and softwoods," Fuel 150, 243 251. DOI: 10.1016/j.fuel.2015.02.045

Xing, Y., Bu, L., Zheng, T., Liu, S., and Jiang, J. (2016). "Enhancement of high-solids enzymatic hydrolysis of corncob residues by bisulfite pretreatment for biorefinery," Bioresource Technology 221, 461-468. DOI: 10.1016/j.biortech.2016.09.086

Yang, H., Shi, Z., Xu, G., Qin, Y., Deng, J., and Yang, Y. (2019). "Bioethanol production from bamboo with alkali-catalyzed liquid hot water pretreatment," Bioresource Technology 274, 261-266. DOI: 10.1016/j.biortech.2018.11.088

Zabaniotou, A. A., Kantarelis, E. K., and Theodoropoulos, D. C. (2008). "Sunflower shells utilization for energetic purposes in an integrated approach of energy crops: 
Laboratory study pyrolysis and kinetics," Bioresource Technology 99(8), 3174-3181. DOI: 10.1016/j.biortech.2007.05.060

Zhao, J. Y., and Chen, H. Z. (2013). "Correlation of porous structure, mass transfer and enzymatic hydrolysis of steam exploded corn stover," Chemical Engineering Science 104, 1036-1044. DOI: 10.1016/j.ces.2013.10.022

Zhu, J., Wang, G., Pan, X., and Gleisner, R. (2009). "Specific surface to evaluate the efficiencies of milling and pretreatment of wood for enzymatic saccharification," Chemical Engineering Science 64(3), 474-485. DOI: 10.1016/j.ces.2008.09.026

Article submitted: September 26, 2019; Peer review completed; December 1, 2019;

Revised version received: December 4, 2019; Accepted: December 7, 2019; Published:

December 18, 2019.

DOI: 10.15376/biores.15.1.1001-1013 